\title{
OS EFEITOS DA CAMUFLAGEM COSMÉTICA NA QUALIDADE DE VIDA DE PACIENTES COM ACNE
}

DOI: $10.22289 / 2446-922 X . V 3 N 2 A 2$

\author{
Raiane Aparecida Gontijo Oliveira \\ Lilian Abreu Ferreira ${ }^{1}$
}

\section{RESUMO}

Algumas dermatoses, por serem aparentes, podem estabelecer consequências na vida pessoal, social e profissional de seus portadores e, devido ao poder de criar impressões e sentimentos, a aparência pessoal pode influenciar na qualidade de vida destes. Em razão disso, pessoas acometidas por problemas dermatológicos como a acne e suas lesões possuem maior propensão em desenvolver problemas de autoestima e estresse psicológico. A acne é uma afecção caracterizada por lesões cutâneas que incluem comedões, pápulas eritematosas, pústulas, nódulos e cicatrizes, sendo a região facial a mais afetada. A camuflagem cosmética pode então, ter uma influência positiva na qualidade de vida dos pacientes com acne. Assim, o objetivo do estudo foi realizar uma pesquisa bibliográfica sobre o uso da camuflagem cosmética em pacientes acometidos pela acne e suas lesões. Foi conduzida uma busca nas bases de dados PubMed e Scopus nos últimos 10 anos, utilizando os termos (MeSH), "cosmetic camouflage", "acne" e "make up". Nos estudos encontrados, foi possível observar que a camuflagem cosmética é um método eficaz para a satisfação imediata dos pacientes, principalmente para aqueles acometidos pela acne, visto que o tratamento terapêutico pode demorar a apresentar os resultados visíveis, e assim, a camuflagem pode ser utilizada de forma complementar a esse tratamento. Alguns estudos mostraram ainda uma melhora na qualidade de vida após o uso da camuflagem para disfarçar as lesões. É necessário educar os pacientes em relação aos produtos mais adequados, escolhidos sob a orientação do profissional de saúde, levando em consideração a terapia farmacológica em andamento.

Palavras-chave: Acne Vulgar; Cosméticos; Qualidade de Vida.

\section{ABSTRACT}

Some dermatoses, being apparent, may have consequences on the personal, social and professional life of their patients and, due to the power to create impressions and feelings, personal appearance can influence their quality of life. As a result, people affected by dermatological problems such as acne and their lesions are more likely to develop self-esteem and psychological stress problems. Acne is a skin disorder characterized by cutaneous lesions

\footnotetext{
${ }^{1}$ Endereço eletrônico de contato: lyabreu@hotmail.com
}

Recebido em 11/09/2017. Aprovado pelo Conselho Editorial e aceito para publicação em 27/09/2017

Rev. Psicol Saúde e Debate. Dez., 2017:3(2):15-29. 
that include comedones, erythematous papules, pustules, nodules, cysts and scars, and the facial region is most affected. Cosmetic camouflage can have a positive influence on the quality of life of acne patients. The aim of the study was to conduct a qualitative bibliographic research on mineral makeup and cosmetic camouflage, emphasizing its use on the skin affected by acne and its lesions. We searched the PubMed and Scopus databases over the last 10 years using the terms (MeSH), "cosmetic camouflage", "acne" and "make up". In the studies found, it was possible to observe that cosmetic camouflage is an effective method for immediate patient satisfaction, especially for those affected by acne, since therapeutic treatment may be slow to present visible results, and thus camouflage can be used in a complementary way on this treatment. Some studies have also shown an improvement in the quality of life after the use of cosmetic camouflage to disguise the lesions. It is necessary to educate the patients so that they use the most suitable products, chosen taking into consideration the pharmacological therapy in progress.

Keywords: Acne Vulgaris; Cosmetics; Quality of Life.

\section{INTRODUÇÃO}

A trajetória da maquiagem teve seu início no Egito, no período paleolítico, sob influência das rainhas egípcias que faziam uso de sombras nas pálpebras e pós no rosto. Desde então, a maquiagem assumiu um importante papel na sociedade com características particulares de cada década, com o objetivo de melhorar a aparência pessoal (Giaboeski, Boehme \& Ellery, 2010; Vita, 2008).

A aparência pode exercer grande influência na qualidade de vida, pois tem o poder de criar impressões e sentimentos. Por isso, pessoas acometidas por problemas dermatológicos como a acne e suas lesões possuem maior propensão em desenvolver problemas de autoestima e apresentar maior nível de estresse psicológico (Levy \& Emer, 2012; Iredale \& Linder, 2009).

A acne é uma doença multifatorial com lesões cutâneas que incluem os comedões abertos e fechados, pápulas eritematosas, pústulas, nódulos, cistos e cicatrizes, sendo a face a região mais afetada. A doença resulta da interação de quatro fatores-chave: aumento da produção de sebo, alteração da queratinização, colonização do folículo pela Propionibacterium acnes e inflamação. As diretrizes atuais de tratamento recomendam terapia de combinação fixa com um retinóide tópico e agente antimicrobiano para a maioria dos pacientes com acne. Existe um interesse crescente na maquiagem como um dos componentes dos planos de manejo da acne (Monfrecola et al., 2016; Thiboutoti et al., 2009; Sabatovich \& Kede, 2009).

A maquiagem surge não só como uma alternativa de camuflar estas lesões, mas também para melhorar e uniformizar o aspecto da pele e, assim, melhorar a qualidade de vida 
dessas pessoas (Giaboeski et al., 2010; Vita, 2008; Rech, Heiderscheidt, Thives \& Rosa, 2010). O conceito de qualidade de vida é amplo e envolve além de aspectos objetivos, aspectos subjetivos como preocupações, estado emocional, metas e expectativas variando de acordo com a cultura pessoal. Muito embora, seja influenciado por aspectos que são universais, como bem-estar físico, psicológico e relações sociais, além de possuir relação também com o estilo de vida, como prática de exercícios físicos e alimentação saudável (Totoro, Sousa, Martins, Chacur \& Souza, 2017; Viana \& Junior, 2017).

Dentro deste contexto, a maquiagem entra como aliada à medicina. Entretanto, é prática comum entre alguns profissionais de saúde desencorajar a aplicação de maquiagens aos pacientes por serem consideradas um dos fatores agravantes para as erupções da acne (Hayashi et al., 2005). A maquiagem mineral e a camuflagem cosmética podem ser, então, uma solução satisfatória (Iredale \& Linder, 2009). A maquiagem mineral é uma alternativa para a maquiagem tradicional, não prejudicial à pele (Iredale \& Linder, 2009).

Particularmente em mulheres, há uma necessidade de produtos cosméticos que possam cobrir eficazmente os sinais mais visíveis da acne para reduzir o impacto emocional da afecção cutânea. O uso da camuflagem pode contribuir para o aumento da adesão dos pacientes com acne ao seu regime terapêutico, que é baixa, estimada em apenas $50 \%$ dos pacientes (Monfrecola et al., 2016; Araviiskaia \& Dreno, 2016; Dréno et al., 2010). Na maioria dos casos, as terapias podem levar várias semanas ou até meses de uso intermitente para alcançar uma melhora notável. O eczema pode melhorar drasticamente com a aplicação de corticosteróides tópicos, inibidores da calcineurina, ou mesmo emolientes no rosto. Entretanto, a acne pode piorar inicialmente após o início do tratamento e levar mais tempo para obter resultados aceitáveis (Levy \& Emer, 2012).

No mercado mundial, a maquiagem movimenta quase 40 bilhões de dólares em todo o mundo, segundo dados do Euromonitor International. Somente no Brasil, essa categoria atingiu em 2012 um valor de cerca de $R \$ 6,8$ bilhões (12,4\%), e a expectativa de evolução até 2017 é de um crescimento anual de 14\% (Abipech, 2014).

A definição de maquiagem mineral sob a ótica da tecnologia farmacêutica é uma maquiagem que não contém talco, substâncias potencialmente irritantes da pele e ingredientes comedogênicos, os quais são críticos para os pacientes acometidos pela acne (Iredale \& Linder, 2009). Não há uma concentração mínima específica de minerais para que o produto seja categorizado como tal, contudo os pós minerais autênticos possuem os minerais como os componentes de maior proporção da composição. Ainda assim, algumas maquiagens são vendidas com o apelo mineral, mesmo contendo uma pequena porcentagem de substâncias químicas em sua composição, como as maquiagens com pigmentos que 
fogem dos tons de pele (marrom e bege), amarelo e preto (Iredale \& Linder, 2009; Castro, Pivo \& Ellery, 2017).

Já a camuflagem cosmética é uma técnica de maquiagem para disfarçar lesões de pele imediatamente, com a intenção de normalizar sua aparência. Esta técnica utiliza produtos especializados, incluindo coberturas em cremes, líquidos e pós como a maquiagem mineral que, quando aplicados de forma sistemática, podem disfarçar rapidamente qualquer área de mudança visível (Levy \& Emer, 2012).

Assim, o objetivo deste estudo foi realizar uma revisão bibliográfica integrativa e qualitativa sobre a maquiagem mineral e a camuflagem cosmética, ressaltando seu uso na pele acometida pela acne e suas lesões. Para tanto, foi conduzida uma busca nas bases de dados PubMed e Scopus nos últimos 10 anos, utilizando os termos (MeSH) "cosmetic camouflage", "acne" e "make up" combinados entre si. Foram selecionados artigos nas línguas inglesa, espanhola e portuguesa, que abordassem o uso da camuflagem cosmética na pele com acne ou em lesões provenientes desta.

Inicialmente, para melhor compreensão dos efeitos da camuflagem, é apresentada uma descrição da fisiopatologia da acne e seus aspectos conceituais, das características da maquiagem mineral e os minerais que a compõem e em seguida as características da camuflagem cosmética e seus efeitos na qualidade de vida dos pacientes.

\section{ACNE}

A acne vulgar é uma afecção cutânea bastante frequente, afligindo de $85 \%$ a $100 \%$ das pessoas em algum momento da vida. Clinicamente se caracteriza por lesões resultantes de ações hormonais que agem sobre as glândulas sebáceas da pele. Ela afeta áreas com maior proporção de folículos sebáceos como a face, parte superior do tórax e dorso (Silva, Costa \& Moreira, 2014; Figueiredo et al., 2011).

É uma doença crônica do folículo pilossebáceo, multifatorial, que possui início na adolescência, com duração variável e pode se estender até a fase adulta. Acomete ambos os sexos, deixando sequelas em alguns casos, porém o sexo masculino é acometido mais gravemente. Estima-se uma incidência de $85 \%$ entre a faixa etária de 12 a 24 anos, e que cerca de $12 \%$ das mulheres e $3 \%$ dos homens continuarão apresentando até os 45 anos de idade (Figueiredo et al., 2011; Rodrigues Neto, Barros, Girão Junior, Lobo \& Fonteles, 2015; Silva et al., 2014).

Rev. Psicol Saúde e Debate. Dez., 2017:3(2):15-29. 
A acne pode ter sequelas físicas como as cicatrizes, bem como psicológicas, afetando a autoestima, o comportamento social e insatisfação estética. Não obstante, a doença pode ser minimizada por um tratamento precoce e eficiente. $O$ tratamento às vezes é deixado de lado, pois não raras vezes o problema é encarado como um processo normal e passageiro, 0 que atrasa a procura de tratamento (Figueiredo et al., 2011; Rodrigues Neto et al., 2015; Silva et al., 2014).

A fisiopatologia da acne ainda não está totalmente esclarecida, é complexa e engloba quatro fatores primários: a hiperplasia das glândulas sebáceas e produção excessiva de sebo, a hiperqueratinização folicular, a colonização do folículo piloso pela bactéria Propionibacterium acnes, e a inflamação e resposta imunológica. Outros fatores como a hereditariedade, stress e a fricção excessiva da pele também podem contribuir para o aparecimento ou agravamento da (Figueiredo et al., 2011; Rodrigues Neto et al., 2015; Silva et al., 2014). A acne se classifica de acordo com o tipo de lesão predominante, nãoinflamatória ou inflamatória. Já em relação às lesões clínicas, pode-se dividi-las em comedões, pústulas e lesões mais graves como os cistos e nódulos. Os comedões são lesões iniciais da acne não-inflamatória, provenientes da hiperqueratinização folicular e da diminuição dos grânulos que revestem a membrana e diferenciam-se em micromedão, comedão fechado e comedão aberto (Hochheim, Dalcin \& Piazza, 2014).

O microcomedão é conceituado como sendo o acúmulo de células de queratina superfície do folículo, no entanto, produz uma extensão folicular não aparente. O comedão fechado caracteriza-se por ser uma elevação cutânea, de cor branca ou amarelada, e pode ser verificado quando há distensão da pele. Há também o comedão aberto, caracterizado como sendo uma lesão plana ou sensivelmente elevada, aparente na superfície da pele, como um ponto de cor castanha ou negra e pode medir até $5 \mathrm{~mm}$ de diâmetro (Sabatovich \& Kede, 2009).

As pápulas e pústulas surgem em casos de evolução da acne. No caso da pápula, os ácidos graxos livres alastram-se pelo folículo pilossebáceo e a inflamação gera uma pápula eritematosa. A pápula é dolorida, e se caracteriza por uma saliência rosa não-pustulosa. Esse tipo de lesão é relativamente superficial e a cicatrização ocorre em um curto período de tempo e, na maioria das vezes, não deixa marcas (Hochheim et al., 2014; Souza \& Antunes Junior, 2009).

A pústula surge em evolução da pápula, apresentando elevação cutânea pustulosa. Como se forma na derme profunda, há grande liberação de material queratinoso para os tecidos adjacentes ocorrendo uma inflamação intensa que se mantém por várias semanas, 
evoluindo para o rompimento. Há formação de crostas e possíveis cicatrizes (Hochheim et al., 2014).

Havendo evolução grave do processo de inflamação, fica nítida a presença de nódulos e cistos. Os nódulos são formações sólidas de pus e sebo, idênticas à pápula, porém com dimensões maiores, de até $2 \mathrm{~cm}$, e possuem reação inflamatória intensa. São vermelhos arroxeados, e a presença de cicatrizes é bastante comum. Podem existir casos de lesões queloidianas permanentes e inestéticas. Já o cisto é um grande comedão que passa por vários processos de ruptura e reencapsulações, possuindo conteúdo caseoso (Silva et al., 2014; Barros, 2009).

Considerando a quantidade e o tipo de lesão, a acne é classificada em: acne grau I, forma não inflamatória e mais leve, evidenciada pela preponderância de comedões abertos ou fechados; acne grau II, forma inflamatória que, além da presença de comedões, têm-se lesões inflamatórias como pápulas e pústulas; acne grau III, forma inflamatória mais acentuada com presença de nódulos e cistos; e a acne grau IV, forma inflamatória severa ou conglobata, contendo todas as lesões citadas anteriormente e a presença de cicatrizes profundas (Costa, Alchorne \& Goldschmidt, 2007).

A classificação clínica da acne determina a escolha do protocolo estético personalizado que irá atuar na forma das lesões. A combinação de técnicas para a utilização no tratamento estará relacionada ao grau de manifestação da doença e à proporção de lesões que estão mais aparentes (Hochheim et al., 2014).

É fundamental um tratamento adequado para a acne devido às suas consequências estéticas de graus variados e impacto psicossocial (Figueiredo et al., 2011; Rodrigues Neto et al., 2015). Estudos recentes destacam os benefícios psicológicos do tratamento das condições dermatológicas, particularmente aquelas que são visíveis em áreas localizadas como rosto, pescoço e mãos. As pessoas acometidas por essas condições, como a acne e suas lesões, possuem maior propensão em desenvolver problemas de autoestima (Levy \& Emer, 2012; Dunn O'Neill \& Feldman, 2011). As condições visíveis da pele são frequentemente uma fonte de preocupação emocional para os pacientes. A adesão em regimes de tratamento prolongados é necessária para que se possam apresentar melhorias visíveis, entretanto, muitos pacientes desejam um efeito imediato (Levy \& Emer, 2012).

É papel do farmacêutico orientar o paciente em relação aos objetivos do tratamento e adesão a fim de controlar a inflamação e impedir infecções secundárias, além de prevenir cicatrizes e lesões permanentes. Além disso, o paciente deve ser orientado quanto às situações desencadeadoras ou agravantes como alimentação, uso de formulações 
farmacêuticas oleosas e comedogênicas (Rodrigues Neto et al., 2013) bem como a introdução da maquiagem e camuflagem cosmética como forma de favorecer o manejo das lesões.

\section{MAQUIAGEM MINERAL COMO ALTERNATIVA PARA PELE COM ACNE}

A maquiagem mineral tornou-se cada vez mais popular nos últimos anos, e embora não haja uma definição padronizada, esses produtos são tipicamente pós soltos contendo principalmente minerais inertes. Ela se diferencia da tradicional por possuir principalmente componentes como o óxido de ferro e zinco, o oxicloreto de bismuto, o dióxido de titânio e a mica. Esses componentes não só fornecem cobertura superior na camuflagem como também oferecem proteção UV, não são comedogênicos e possuem ação anti-inflamatória. Ademais, a maquiagem mineral é livre de agentes potencialmente irritantes e comedogênicos, os quais são críticos para os pacientes com acne, como por exemplo o talco, corantes sintéticos, fragrâncias e parabenos (Iredale \& Linder, 2009; Castro et al., 2017; Gomes \& Damazio, 2013).

Pacientes com acne frequentemente buscam opções para cobrir o que eles consideram condições de frustração visual, e muitas vezes fazem escolhas que não são eficazes ou são potencialmente prejudiciais à sua situação. Para oferecer melhores opções a esses pacientes, os médicos e farmacêuticos devem educar sobre as opções de camuflagem. A maquiagem mineral pode ser uma solução satisfatória, pois é uma alternativa à maquiagem tradicional, não prejudicial à pele (Iredale \& Linder, 2009).

Esse tipo de maquiagem corrige algumas imperfeições, uniformizando a tonalidade da pele. A alta concentração de minerais da formulação também dá a aderência de pó que raramente necessita de reaplicação, o que os torna utéis para pacientes que desejam soluções rápidas e práticas (Castro et al., 2017).

Os minerais utilizados em pós minerais são inorgânicos, definidos como moléculas sem carbono. Os compostos de carbono são a base para todos os organismos vivos; já os inorgânicos são os compostos dos não-vivos ou de origem mineral ao invés de origem biológica. A natureza inerte elimina o risco de contaminação microbiológica, contrastando com o orgânico, o qual requer conservantes para prevenir a contaminação. Nenhum dos minerais formulados em pós cosméticos são diretamente retirados da terra e utilizados, sendo alguns inteiramente fabricados, com a maioria passando por extensos processos de refinação. O óxido cloreto de bismuto é encontrado como o mineral bismuto na crosta terrestre e em certos tipos de minérios. Ele requer considerável refinamento e purificação

Rev. Psicol Saúde e Debate. Dez., 2017:3(2):15-29. 
antes que possa ser usado topicamente. Os óxidos de ferro usados para cosméticos são totalmente sintetizados para evitar a contaminação por metais pesados presentes na natureza (Iredale \& Linder, 2009).

Não existem muitas pesquisas divulgadas sobre a maquiagem mineral, bem como de seus ativos minerais. Do mesmo modo, ainda há vários questionamentos sobre os benefícios da maquiagem mineral. Diante disso, é estudos referentes à composição da maquiagem mineral e as suas consequências (Castro et al., 2017).

\section{OS MINERAIS PRIMÁRIOS UTILIZADOS NA MAQUIAGEM}

Os minerais primários podem ser utilizados sozinhos ou em combinação para maximizar os benefícios e a efetividade da maquiagem mineral (Iredale \& Linder, 2009).

A mica é um mineral manufaturado com brilho cristalino, capaz de trazer um ótimo deslizamento e aderência ao produto, além de adicionar brilho ao mesmo. A mica natural não tem sido utilizada em cosméticos desde os anos 60 . Pertence ao grupo de minerais de silicato de potássio hidratado e pode ser utilizada como corante, proporcionando efeito cintilante em pós de maquiagem, dependendo do tamanho da partícula. Em tamanhos maiores é usada para brilho, e em partículas menores, para efeito fosco e ação absorvente em benefício de pacientes com pele oleosa. É encontrada em diversas colorações, inclusive incolor (Giaboeski et al., 2010; Iredale \& Linder, 2009; Castro et al., 2017; Michalun \& Michalun, 2010).

O dióxido de titânio atribui à pele uma excelente cobertura, pois é uma partícula de pigmento em pó branco apto a formar uma barreira sobre a pele e com capacidade de bloquear os raios UV. Ele é aprovado como um filtro físico em protetores solares e antiinflamatório (Sadrieh et al., 2010).

O dióxido de titânio figura entre os 21 filtros aprovados pelo FDA, para uso com concentração entre $2 \%$ e $25 \%$. Ao ser aplicado na pele, ele continua sob sua superfície, pulverizando a luz UV. O tamanho do dióxido de titânio é condição essencial para o fim de incorporá-lo em formulações de filtro solares, bases para maquiagem e hidratantes diurnos. Isso porque quando a partícula é menor, menos obstrutiva será a aplicação do dióxido de titânio (Michalun \& Michalun, 2010; Sadrieh et al., 2010).

O caulim (argila de caulim) é uma combinação de vários silicatos de alumínio, utilizado frequentemente em pós e máscaras em virtude de suas propriedades absorventes, abrasivas, encorpantes, opacificantes e não comedogênicas. Possui excelente capacidade e cobertura 
e adesão na pele, além de absorver o óleo e água secretados pela pele (Michalun \& Michalun, 2010).

Outro ativo é o estearato de zinco, uma mistura de sais de zinco e palmítico, com propriedades adesivas e corantes em formulações cosméticas (Castro et al., 2017). O óxido de zinco é extraído do minério de zinco, e facilmente encontrado em seu estado natural. É um mineral branco puro conhecido por suas propriedades anti-inflamatórias e antimicrobianas, e é aprovado como filtro físico de protetores solares. É um excelente protetor contra as radiações UVA e UVB. É comumente utilizando quando se almeja uma cor branca ao produto, e raramente causa alergias (Castro et al., 2017).

Os óxidos de ferro são principalmente utilizados como corantes e, combinando as três tonalidades de sua composição, amarelo, preto e vermelho, com o dióxido de titânio, é possível obter várias tonalidades para a pele. Devido à presença de metais pesados, não deve ser utilizado diretamente da natureza, devendo ser sintetizado em laboratório (Giaboeski et al., 2010; Iredale \& Linder, 2009).

Já o oxicloreto de bismuto com origem a partir do mineral bismuto é processado para a obtenção de um pó metálico branco ou quase branco. É utilizado em cosméticos, proporcionando efeito perolado. Seu brilho levou-o a ser chamado de pérola sintética. De todos os componentes minerais, este é um dos que possui potencial de irritação (Castro et al., 2017).

\section{CAMUFLAGEM}

A técnica de maquiagem no contexto de assistência à saúde somente foi introduzida após a Segunda Guerra Mundial, na reabilitação de pilotos que foram severamente queimados. Atualmente, a camuflagem cosmética tem sido empregada à prática dos profissionais de saúde para corrigir desfigurações adquiridas ou congênitas não passíveis de tratamento médico ou cirúrgico ou mesmo temporariamente, até que se alcance os efeitos desejáveis de um tratamento farmacológico (Antoniou \& Stefanaki, 2006).

A camuflagem cosmética é uma técnica que usa maquiagem para disfarçar lesões da pele imediatamente, com a intenção de normalizar a aparência da pele. A importância da camuflagem não pode ser subestimada nos indivíduos acometidos pela acne devido à sua influência na qualidade de vida e autoimagem desses indivíduos (Goh et al., 2016; Antoniou \& Stefanaki, 2006; Padilla-Espanã, del Boz, Ramírez-López \& Fernández-Sánchez, 2014).

Rev. Psicol Saúde e Debate. Dez., 2017:3(2):15-29. 
É possível cobrir os sinais visíveis da acne através de uma forma recomendada por um profissional de saúde, pois sem estas escolhas informadas, o paciente pode escolher um produto que não é adequado e, com isso, piorar sua condição dermatológica (Melville \& Nancy, 2007; Matsuoka et al., 2006). Ademais, os cosméticos que são acnegênicos em um paciente não necessariamente são em outro, além de ser uma característica distinta da comedogenicidade. A formação de acne causada por cosméticos é rápida, geralmente se desenvolvendo dentro de 48 a 72 horas após a aplicação do produto (Iredale \& Linder, 2009).

A camuflagem cosmética se distingue da maquiagem tradicional por utilizar produtos especializados que, quando aplicados de forma sistemática, podem disfarçar rapidamente qualquer área de mudança visível. Os produtos possuem formulação mais consistente, impermeáveis e opacos, contribuindo para disfarçar as imperfeições. Com isso, a camuflagem cosmética é uma maneira de camuflar as lesões na pele com resultado imediato após a aplicação do produto (Figura 1 e 2), além de alcançar uma melhora na adesão do paciente e em sua autoestima (Levy \& Emer, 2012; Castro et al., 2017).

Dentro desse contexto, os pós minerais têm sido usados para efeito positivo por dermatologistas, cirurgiões plásticos e outros profissionais da estética por cerca de 15 anos para a camuflagem de imperfeições de todos os tipos de pele. Além disso, é possível encontrar várias tonalidades para combinar e se adequar ao tom e condição da pele. Com isso, à frente da aplicação, a proporção de cores é primordial na otimização da cobertura sobre a acne e rosácea. Alguns estudos recomendam a cor verde para neutralizar as áreas eritematosas e os tons bege/amarelo para as áreas hiperpigmentadas (Goh et al., 2016; Padilla-Espanã et al., 2014; Couteau, Paparis \& Coiffard, 2016).
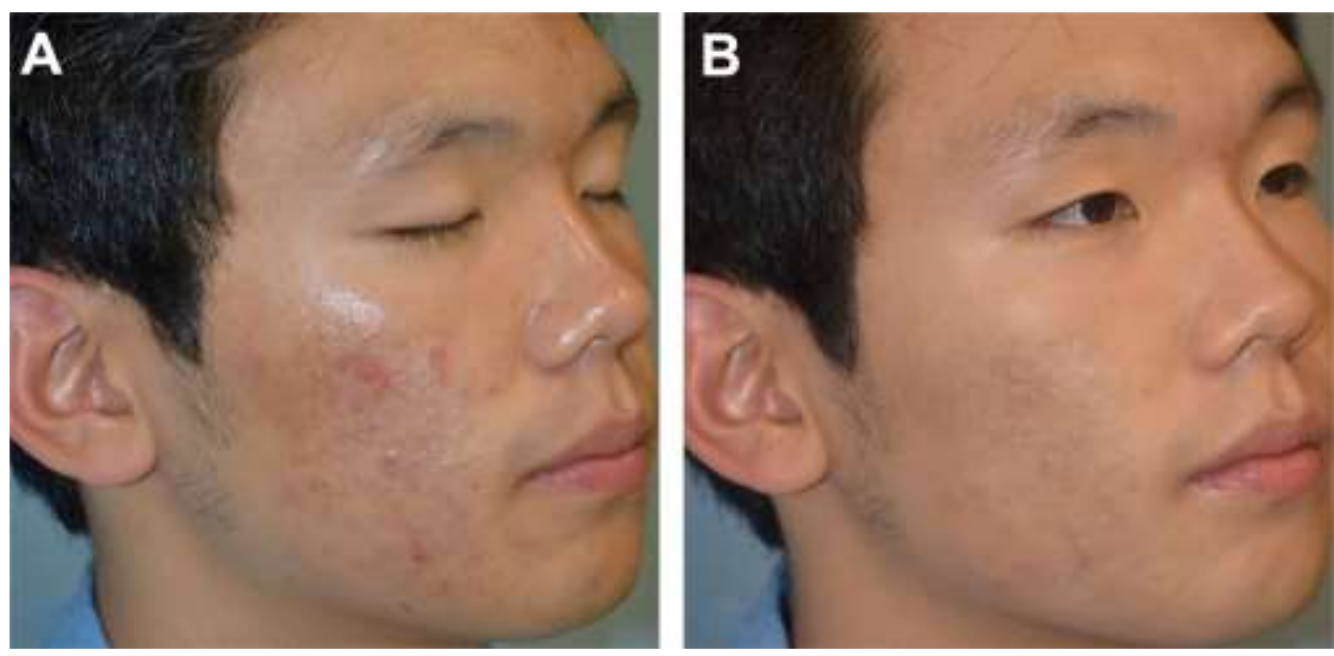

Figura 1: Paciente com acne severa. Antes e (B) Depois da camuflagem cosmética. Fonte: (Levy \& Emer, 2012)

Rev. Psicol Saúde e Debate. Dez., 2017:3(2):15-29. 

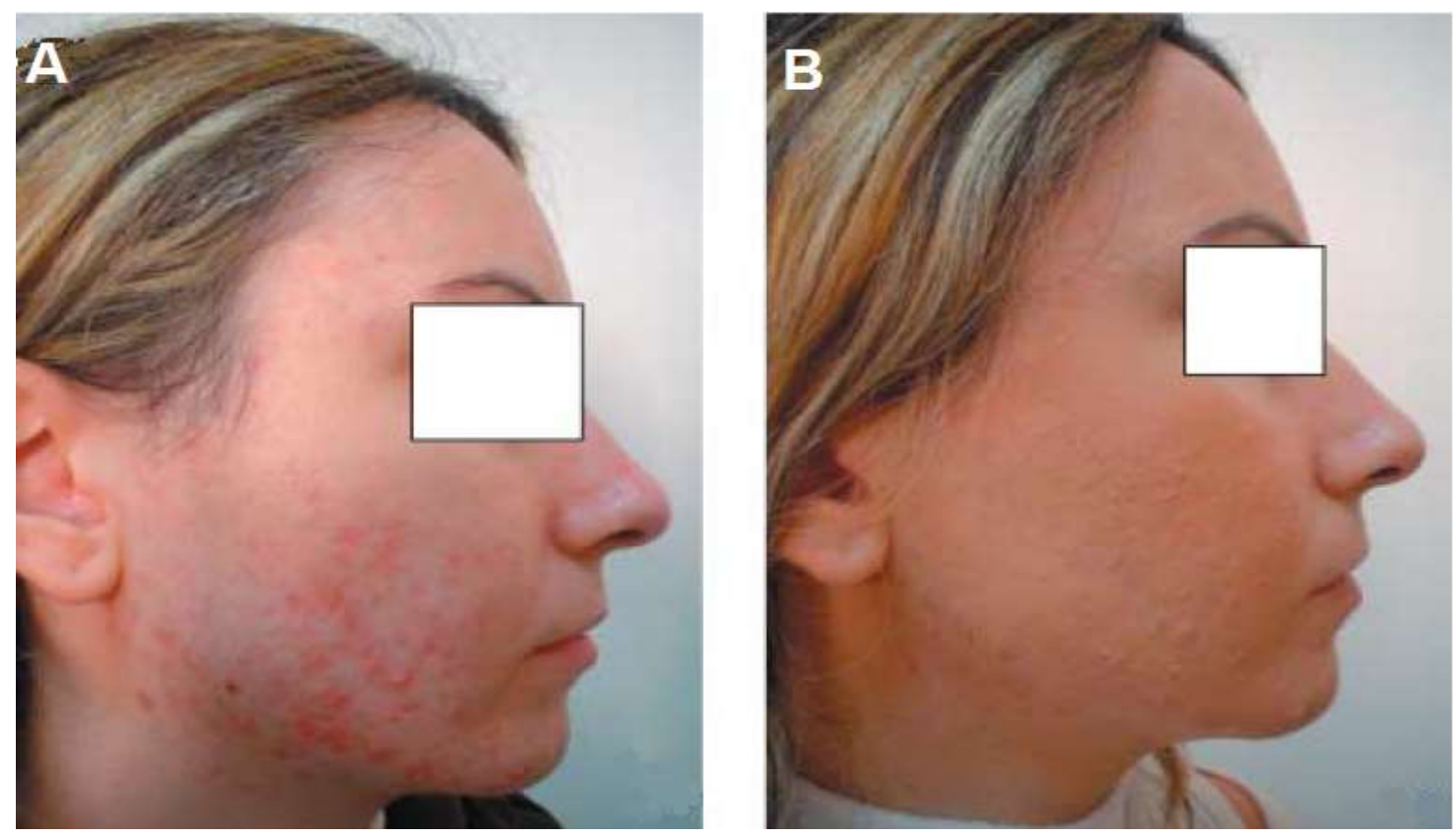

Figura 2: Paciente com acne. (A) Antes e (B) Depois da camuflagem cosmética. Fonte:

(Antoniou \& Stefanaki, 2006)

Entretanto, alguns autores afirmam que esta contraposição de cores não combina na pele e que, para cobrir com eficiência a vermelhidão causada pelo eritema da acne, por exemplo, as melhores escolhas são os tons amarelados. Se o eritema não for tão pronunciado, uma cor equivalente ao tom de pele pode ser aplicada e, caso não seja obtida a cobertura suficente, um tom amarelado deve ser aplicado antes da cobertura na cor equivalente ao tom da pele (Iredale \& Linder, 2009; Couteau et al., 2016).

Uma camuflagem cosmética ideal para acne deve ter uma aparência natural, nao ser irritante, comedogênica ou acnegênica, além de possuir fácil aplicação. A escolha dependerá da preferência do paciente pela paleta de cores disponíveis, da presença de componentes específicos, como os beta-hidroxiácidos naturais presentes no extrato da casca de salgueiro ou óleos essenciais, como por exemplo a Matricaria recutita, que possui propriedades antiinflamatórias e antimicrobianas, ou vitaminas com propriedades antioxidantes, como a vitamina (Levy \& Emer, 2012; Goh et al., 2016) .

Em um estudo realizado por Matsuoka e colaboradores, foi avaliado se o uso da maquiagem e cuidados com a pele poderia influenciar a qualidade de vida dos pacientes afetados sem prejudicar os tratamentos convencionais da acne. Ao todo 50 pacientes com acne do sexo feminino foram recrutadas. Os autores concluíram que as instruções sobre a 
maquiagem influenciaram efetivamente a qualidade de vida das pacientes após 4 semanas de tratamento, e sugerem que os cosméticos podem complementar o tratamento convencional da acne (Matsouka et al., 2006).

Com o objetivo de avaliar uma formulação patenteada de camuflagem cosmética para a acne, foi realizado um estudo piloto em 20 mulheres com acne em um período de 28 dias. Foram avaliados a tolerabilidade, comedogenicidade e o efeito de cobertura. A avaliação da tolerabilidade mostrou que as reações cutâneas, incluindo eritema, edema, secura, descamação, sensação de repuxo, prurido e queimação, foram ausentes em todos os pacientes. A formulação não apresentou característica comedogênica e proporcionou uma significativa redução de $15,8 \%$ nas lesões da acne facial após os 28 dias $(P<0,001)$. Proporcionou também um bom efeito de cobertura 30 minutos após a aplicação em $80 \%$ dos pacientes. Todos os pacientes (100\%) ficaram satisfeitos e $80 \%$ afirmaram que a pele melhorou (Monfrecola et al., 2013). Com a formulação adequada, é possivel combinar maquiagem e tratamento de forma complemetar melhorando a adesão do paciente.

Em um estudo de caso, um paciente de 15 anos de idade, do sexo masculino com cicatrizes de acne, recebeu uma única sessão de camuflagem com duplo objetivo, um prático e outro didático, para que fosse observado o impacto na melhoria da qualidade de vida do paciente, bem como para que tanto ele e seus familiares adquirissem noções básicas de aplicação da maquiagem de forma independente em domicílio. Foi registrada uma melhora na qualidade de vida de forma global quando comparada à avaliação prévia ao estudo após a aplicação e transcorrido o período de duas semanas e seis meses (Padilla-España et al., 2014).

\section{CONSIDERAÇÕES FINAIS}

A camuflagem cosmética torna-se cada vez mais um método para ajudar na satisfação imediata dos pacientes, contribuindo assim para a melhoria na qualidade de vida. Dentro desse contexto, a maquiagem mineral autêntica funciona de forma diferente da maquiagem tradicional pelos benefícios oferecidos principalmente para a pele com acne. É necessário educar os pacientes para que eles usem os produtos mais adequados, escolhidos levando em consideração a terapia farmacológica em andamento. É importante que os profissionais de saúde da área cosmética forneçam esta opção após a consulta inicial não só pelos resultados imediatos, mas também de modo complementar enquanto aguardam os efeitos do tratamento farmacológico.

Rev. Psicol Saúde e Debate. Dez., 2017:3(2):15-29. 


\section{REFERÊNCIAS}

Abihpech, III Caderno de Tendências 2014/2015. [Acesso em 01 nov 2016]. Disponível em: http://www.abihpec.org.br/conteudo/caderno tendencias.pdf.

Antoniou, C. \& Stefanaki, C. (2006). Camuflagem cosmética. J Cosmet Dermatol:;5:297-301.

Araviiskaia, E. \& Dreno, B.(2016). The role of topical dermocosmetics in acne vulgaris. J Eur Acad Dermatol Venereol.;30(6):926-35.

Barros L. Dicionário de dermatologia. (2009). São Paulo: Cultura Acadêmica.

Castro, J., Pivo, M., Ellery, F. (2017). Maquiagem Mineral: Uma análise do produto brasileiro [Graduação]. UNIVALI. [Acesso em 10 de agosto 2017]. Disponível em: http://siaibib01.univali.be/pdf/jessica\%20castro,\%20monica\%20piva.pdf.

Costa, A., Alchorne, M.A. \& Goldschmidt, M.C.B. (2008). Fatores etiopatogênicos da acne vulgar. An Bras Dermatol.;83:451-9.

Couteau, C., Paparis, E. \& Coiffard, L.J. (2016). BB creams and their photoprotective effect. Pharm Dev Technol. 2016; 21:39-42.

Disponível

em:

http://siaibib01.univali.br/pdf/Adriana\%20Giaboeski,\%20Fernanda\%20Boehme.pdf.

Dréno, B., Thiboutot, D., Gollnick, H., Finlay, AY., Layton, A., Leyden, J.J. Leutenegger, E., Perez, M. Global Alliance to Improve Outcomes in Acne. (2010). Large-scaleworldwide Observational studyo fadherencewith acne therapy. Int J Dermatol.;49(4):448-56.

Dunn, L.K., O'Neill, J.L., \& Feldman, S.R., (2011). Acne in adolescents: quality of life, selfesteem, mood, and psychological disorders. Dermatol Online J;17(1):1.

Figueiredo, A., Massa. A., Picoto, A., Soares, A.P., Sousa-Basto, A., Lopes, C., Resende, C., Rebelo, C., Brandão, F.M., Marques-Pinto, G., Oliveira, H.S., Selores, M., Gonçalo, M., Bello, M. T. (2011). Avaliação e tratamento do doente com acne - Parte I: Epidemiologia, etiopatogenia, clínica, classificação, impacto psicossocial, mitos e realidades, diagnóstico diferencial e estudos complementares. Rev Port Clin Geral. [acesso 13 Jun 2017]; 27:59-65. Disponível em: http://www.scielo.mec.pt/pdf/rpcg/v27n1/v27n1a11.pdf.

Giaboeski, A., Boehme, F., Ellery, F. (2010). Maquiagem Mineral: uma descrição das suas características no mercado cosmético. [Acesso em 27 nov 2016]. Disponível em: http://siaibib01.univali.br/pdf/jessica\%20castro,\%20monica\%20piva.pdf.

Goh, C.L., Noppakun, N., Micali, G., Azizan, N.Z., Boonchai, W., Chan, Y., Wong, S.N. (2016). Meeting the Challenges of Acne Treatment in Asian Patients: A Review of the Role of Dermocosmetics as Adjunctive Therapy. Journal of Cutaneous and Aesthetic Surgery, 9(2), 85-92.

Gomes, R. \& Damazio, M. (2013). Cosmetologia: Descomplicando Os Princípios Ativos. São Paulo: Livraria Médica Paulista.;4. 
Hayashi, N., Imori, M., Yanagisawa, M., Seto, Y., Nagata, O., Kawashima, M. (2005). Makeup improves thequality oflifeof acne patients withoutag gravating acne eruptions during treatments. Eur J Dermatol; 15 (4): 284-7.

Hochheim, L., Dalcin, P., \& Piazza, F. (2014). Princípios básicos para o tratamento cosmético da acne vulgar. UNIVALI; [acesso 14 jun 2017] Disponível em: https://pt.scribd.com/document/250094547/Principios-Basicos-Para-o-Tratamento-Da-Acne-

Vulgar.

Iredale, J.M.A., \& Linder, J.M.D. (2009). Mineral make-up and its role with acne and rosácea. Cosmetic Dermatology; 22:407-12.

Kede, M., \& Sabatovich, O. (2009). In Dermatologia estética. São Paulo: Atheneu.

Levy, L.L., \& Emer, J.(2012). Emotional Benefit of Cosmetic Camouflage in the Treatment of Facial Skin Conditions: Personal Experience and Review. Clinical, Cosmetic and Investigational Dermatology.; 5:173-82.

Matsuoka, Y., Yoneda, K., Sadahira, C., Katsuura, J., Moriue, T., Kubota, Y. (2006). Effects of skin care and makeup under instructions from dermatologists on the quality of life of female patients with acne vulgaris. J Dermatol. 33:745-52.

Melville, N.A., \& Nancy, A. (2007) Camouflage makeup evolves. Dermatology Times.

Michalun N, Michalun M.(2010). Dicionário de Ingredientes para Cosmética e Cuidados da Pele. São Paulo: Senac.;3.

Monfrecola, G., Gaudiello, F., Cirillo, T., Fabbrocini, G., Balato, A., Lembo, S.(2013) Nicotinamide down regulates gene expressionof interleukin-6, interleukin-10, monocy techemo attractant protein-1, and tumour necrosis factor-alpha gene expression in $\mathrm{Ha} \mathrm{CaT}$ keratino cytesafter ultraviolet B irradiation. Clin Exp Dermatol. ;38(2):185-8.

Padilla-España, L., del Boz, J., Ramírez-López, M.B., \& Fernández-Sánchez, M. E. (2014). Camouflage therapy workshop for pediatric dermatology patients: a review of six cases. Actas Dermosifiliogr.;105(5):510-514.

Rech, G., Heiderscheidt, I., Thives, F.M., \& Rosa, F.A. (2010). Camuflagem cosmética: o uso da maquiagem para a correção dos defeitos da pele. Trabalho de Conclusão de Curso de Cosmetologia e Estética da Universidade do Vale do Itajaí - UNIVALI. [Acesso em 14 set 2016] Disponível em: http://siaibib01.univali.br/pdf/Gabriela\%20Rech\%20e\%20lsete\%20Heiderscheidt.pdf.

Rodrigues Neto, E.M., Barros, K.B.N.T., Girão Junior, F.J., Lobo, P.L.D., \& Fonteles, M.M.F. (2015) Abordagem Terapêutica da Acne na Clínica farmacêutica. Boletim Informativo Geum.;6:1-8.

Rodrigues Neto, E.M., Marques, L.A.R.V., Lotif, M.A.L., Coelho, M.O., Nocrato, M.N., Rodrigues, J. C. (2013). Dermatite Seborreica: Abordagem Terapêutica No Âmbito Da Clínica Farmacêutica. Revista Eletrônica de Farmácia.;10(4),11.

Sadrieh, N., Wokovich, A. M., Gopee, N. V., Zheng, J., Haines, D., Parmiter, D., Siitonen, P.H., Cozart, C. R., Patri, A. K., McNeil, S. E., Howard, P. C., Doub, W. H., Buhse, L. F. 
(2010). Lack of significant dermal penetration of titanium dioxide from sunscreen formulations containing nano- and submicron-size TiO2 particles. Toxicol Sci; 115:156-66.

Silva, A., Costa, F., Moreira, M. (2014). Acne Vulgar: diagnóstico e manejo pelo médico de família e comunidade. Revista Brasileira de Medicina Família e Comunidade; 55-63.

Souza, V.M., \& Antunes-Junior, D.(2009). Ativos dermatológicos: guia de ativos dermatológicos utilizados na farmácia de manipulação para médicos e farmacêuticos. São Paulo: Pharmabooks.;5:640.

Thiboutot, D., Gollnick, H., Bettoli, V., Dréno, B., Kang, S., Leyden, J. J., Shalita, A. R., Lozada, V. T., Berson, D., Finlay, A., Goh, C.L., Herane, M. I., Kaminsky, A., Kubba, R., Layton, A., Miyachi, Y., Perez, M., Martin, J. P., Ramos-E-Silva, M., See, J. A., Shear, N., Wolf, J., Jr. Global Alliance to Improve Outcomes in Acne. (2009). New insights into the management of acne: an update from the Global Alliance to Improve Outcomes in Acne group. J Am Acad Dermatol. ;60(5 Suppl): S1-S50.

Totoro, R., Sousa, M., Martins, R., Chacur, E., \& Souza, F. (2017). Avaliação da qualidade de vida dos usuários de um núcleo de apoio à saúde da família - Nasf. Psicologia e Saúde em Debate. 3:50-67.

Viana, A., Junior, G.A. (2017). Qualidade de vida em idosos praticantes de atividades físicas. Psicologia e Saúde em Debate, 3(1): 87-98.

Vita, A.C.R. (2008). História da maquiagem, da cosmética e do penteado: em busca da perfeição. São Paulo: Anhembi Morumbi. 